\title{
Correction to: Maternal diabetes and risk of childhood malignancies in the offspring: a systematic review and meta-analysis of observational studies
}

\author{
Pengfei Yan ${ }^{1} \cdot$ Yongbo Wang $^{2} \cdot$ Xue Yu $^{1} \cdot$ Yu Liu $^{3} \cdot$ Zhi-Jiang Zhang $^{1}$ (I)
}

Published online: 2 February 2021

(c) Springer-Verlag Italia S.r.l., part of Springer Nature 2021

\section{Correction to: Acta Diabetologica https://doi.org/10.1007/s00592-020-01598-2}

Authors would like to correct the error in in their original publication of the article.

The misspelling of "Identification" in Fig. 1 is corrected. The misuse of "Finnish" is corrected to "Finland" including Fig. 2, Fig. 3, Table 1 and in the text (Study characteristics).

The original article has been corrected.

The original article can be found online at https://doi.org/10.1007/ s00592-020-01598-2.

\section{Zhi-Jiang Zhang}

zhang22968@163.com

1 Department of Preventive Medicine, School of Health Sciences, Wuhan University, Wuhan 430071, China

2 Center for Evidence-Based and Translational Medicine, Zhongnan Hospital of Wuhan University, Wuhan 430071, China

3 Department of Statistics and Management, School of Management, Wuhan Institute of Technology, Wuhan 430205, China
Publisher's Note Springer Nature remains neutral with regard to jurisdictional claims in published maps and institutional affiliations. 